\title{
A Discussion on Entrepreneurship, Creativity, and Innovation Applied to International Marketing
}

\author{
Edmir Kuazaqui \\ Escola Superior de Propaganda e Marketing (ESPM), São Paulo, Brazil
}

\begin{abstract}
This article seeks to discuss the importance of the need to undertake, create, and innovate in Administration, especially considering the international market. For development, it is presented in a contextualized manner, the evolution of organizations throughout the ages and its importance in an economic and social point of view. Within this vision, the entrepreneur is differentiated from the business person, evidencing the individual entrepreneur and the creative economy as fomenters of new business opportunities. In a society in which there are no more borders, only the political and cultural ones, enterprise, creativity, and innovation become necessary as a means for differentiated and sustained growth, especially considering domestic and international competition. As human skills applied to the professional field, people can use them in a handcrafted and differentiated manner, to render the strategies of the actions into ways of modeling businesses and solutions, thus reaching a state of the art.
\end{abstract}

Keywords: entrepreneurship, creativity, innovation, international marketing, competences, administration

\section{Introduction}

The administration stands out for having a direct corporate application. Institutions for Higher Education (IHE), through their superior graduate programs, seek to offer courses that prepare their students for the challenges of the corporate market. This is done through management indicators that related fields such as finance, personnel management, production, and marketing intercommunicate with internal and external environments, enabling, in a rational and systemic thinking, a full use of resources to obtain the best corporative results. In this respect, many authors, such as Chandler (2001), understood that the administration should be more processual, involving the management as well as allocation, monitoring and coordination of resources, and restricting other factors such as knowledge and experience within a more strategic vision, taking into account competitiveness and cooperation as alternatives that influence professionals to endeavor. Therefore, the administration cannot be treated as an exact science, which deals with the relations among the trinomial: markets-company-resources, seeing that it deals with the relationships between people and their respective potentials, with differentiated levels of knowledge, vision, and interconnectivity.

The understanding of this reality causes the company to adopt ways of acting with strategies focused on individuals, differentiating it from direct and indirect competitors. They should, within their bounds, reflect and rethink their concepts and paradigms, to practice the science of administration in a creative, innovative, and

Edmir Kuazaqui, Ph.D., Master in Administration, professor of Escola Superior de Propaganda e Marketing (ESPM), São Paulo, Brazil.

Correspondence concerning this article should be addressed to Edmir Kuazaqui, Alencar de Araripe Street, 1517, São Paulo, SP, Brazil, zip code 04253-000, Brazil. E-mail: ekuazaqui@uol.com.br. 
entrepreneurial, sometimes rationally and other times emotional form, in the sense of breaking paradigms and overcoming challenges or even creating them. This direction may have its risks, but it is only with this daring that tomorrow may also be the time to harvest many successes.

Thus, this study discusses how entrepreneurship, creativity, and innovation can be used in professional practices in companies.

\section{Methodology}

On one hand, entrepreneurship, creativity, and innovation are treated here as human skills and for this reason this paper preferred a strand of qualitative research, since the proposed article is to discuss, in a contextualized manner, the incorporation of such practices in professional life and not indicate statistically those practices that have already been carried out. On the other hand, the interpretation and analysis of practices in this category are very difficult, because undertaking is not only repeating already consecrated actions, but also having the ability to create other different ones.

According to G M. M. Gergen and K. Gergen (2006), "The field of qualitative research is full of enthusiasm, creativity, intellectual effervescence and action", therefore the goal is to present insights on the proposed topics.

As for methods, initially an inductive one was used, because according to Lakatos and Marconi (2003),

Inductive arguments allow for varying degrees of force, depending on the capacity of the premises to support the conclusions. In short, inductive arguments increase the contents of the premises, while deductive arguments are sacrificing the content expansion to achieve "certainty". (p. 267)

The premises are based on the assumption that most times, the use of such human skills brings significant and positive contributions to any type of business. Such practices are a consequence of the capacity of the Institutions for Higher Education (IHE) to apply teaching techniques and especially education, through active learning and practices that translate the human skills practiced in a corporate environment that vary in accordance with the endogenous and exogenous motivations of each person. This depends on their training and personal, as well as, professional life cycle. Another method used, to confirm certain premises, was case study, which ensured a certain tangibility in the light of the theory presented.

The case studies are presented in a simplified form in the final topic of this article. They allow for knowing the capacity of entrepreneurship, creativity, and innovation from a sample composed by students of the penultimate semester of the administration course who have chosen to include three additional disciplines (termed as minors, a sort of specialization in international business management) to their normal curriculum. The average age is 21 years of age and almost all are in professional activity, usually in a required supervised internship. The case studies are developed from research by the author as a company consultant and later on selected in accordance with the objectives of each application.

The first case study, after developing and discussing the concepts, is read and discussed. This practice serves as a warming up for the students. Subsequently, the following questions were brought forth: What lessons can be drawn from this case study? How does one evaluate the posture of the new manager? How do you evaluate the change in the employee's behavior? Do you consent to the release of resources by the Finance area and not the personnel management area? What recommendations would you give to the company in relation to the assessment of performance and motivational aspects of their internal collaborators? 
This small real case explores the influences of endogenous and exogenous variables on the individual and how the environment, generating motivation to do it differently, can stimulate them.

In the second case, the following questions were asked: What lessons can one learn from this case study? What impressions did you get of the company's posture? What impressions did you get of the employee's posture? What is, in reality, the problem of the company? What recommendations can be made to the company to promote commitment on the part of the new trainees, thus lowering a high turnover?

The objectives of this second real case study were the contextualized discussion of the importance for strategic planning and resource management to ensure the effectiveness, efficiency, and efficacy of the company in order to ensure stronger and more solid evaluation and control.

The third case study, in turn, had the following issues: contextualizing the need to undertake, innovate, and create with this case study; reviewing the points in common and the differences between them. What is the relationship with the proposed themes? What influence does culture have on this case? What would happen if this same fact were to occur in a European country? How can cultural variables have influence on the business development of a company? How to they analyze the example of the mobile hot tub? Make a deeper study into the case itself. What business lessons can they obtain from it?

This case study aimed to discuss the importance of understanding cultural diversity and respect for different cultures that influence the decisions of international marketing.

The fourth and final case study brought the following questions: What benefits can be evidenced from the decision of internationalization at the time in which the process began? Do you consider the internationalization of the enterprise to be entrepreneurial, creative, or innovative? Which scenario could be described today and had the company decided to become internationalized? What is the relationship of the case study with the contents of international marketing? What benefits does the company have, at present, stemming from the reality of working in about 50 countries?

As a conclusive example, this case study aims to present and discuss a well-known corporate case, with greater magnitude that significantly influenced the development and sustained growth of a company at a time when, neither discussing internationalization nor human competences were discussed as they are nowadays.

The script of questions was adequate to the content of the discussions and served as parameter for understanding the application of the case studies.

For techniques, aside from bibliographical, field research was used along with classroom practice. It should be noted, once again, that the focus here is on human skills and not on international marketing or the didactics of higher education, so as not to blur the objectives of this article.

\section{Administration and the Need to Undertake, Create, and Innovate}

In imperial Japan, the main source of carbohydrates came from rice, an ancient and cultural food. For cultivating paddy fields, several inputs, in addition to land-flooded plains, are necessary such as, grain selection for planting, human labor for planting and harvesting and storage maintenance, etc.. In addition to these, other factors, such as climate, pests, and even disasters, can influence the outcome of the process.

Thus, Japanese folk wisdom seemed to have already detected, since ancient times, that, with the exception of the external factors, over which one had no control, others could be optimized by the planned use of resources and improving the results. With this in view, it became normal to breed fish in the wetlands, which contributed to the paddy fields being free of some pests, seeing that the fish fed on insects that roamed there. 
These in turn, were fertilized naturally and at the end of the period, productivity had grown considerably, with a lower use of resources and less human handling.

From this example, one might note that administration may be seen within the scope of the IHE, because it was constituted as a case study, as the individual within the scope of the company, and that all of them have the market as a connection. This connectivity influences the economic growth of a country from the ability of companies to undertake and innovate. Schumpeter (1949) already evidenced trinomial entrepreneurship-creativity and innovation, defining the need of the manager to endeavor coming from high creativity, obtaining significant results from innovations. Drucker (2006) complemented the concept, introducing the possibility of the risk of new ventures. According to Markatou and Stournaras (2013), "Economic growth relies on both the fostering of entrepreneurship and the production of innovation. In fact there is wide acknowledgment of the significant role played by entrepreneurship and innovation in economic growth" (p. 1).

The need for survival causes individuals and companies to seek solutions for their problems. Nowadays, winners must create their challenges to maintain growth and development constancy. They should seek answers for questions that have been very well prepared.

\section{Corporate Point of View: Evolution and Life Cycles of Organizations}

Companies have changed in recent decades. In the past, they had a larger group of employees and little productivity in comparison to the current reality. Today, they have had to mold themselves to the changes and transformations of the environment.

Adizes (1999) commented that,

It may be new to you if I say that we all experience changes and that the changes are a phenomenon that will exist as long as we can perceive anything. Changes give rise to events that can be opportunities or problems. (p. 3)

The changes in the environment, in which enterprises are inserted, can be derived from structural and/or cyclical factors of the society. Structural factors are related to the percentage of participation of the basic sectors in the economy, such as agriculture and livestock as well as at the industrialization level of a country. Therefore, the higher the industrialization percentage in the economy, the better structure companies that serve the market will have. Sometimes, some behaviors are predictable, from their historical recurrence. However, cyclical factors are those framed as situational, which eventually occur and do not repeat themselves. In agriculture, for example, it can be a drought. These are facts that represent short-term temporary situations, and do not occur frequently. According to Kotler and Armstrong (1999), industrial structures can be classified as: subsistence economies, exporters of raw materials, semi-industrialized and industrialized, according to their production and consumption particularities.

In this way, one can associate the structure of companies with the country's industrial and economic moment. The greater the challenges, the better the organizational structures are. Another way to assess the life cycle of organizations can be associated with its size and organizational history. According to Geus (2002), companies can go through the following life cycle phases: birth, adolescence, adulthood, and maturity, depending on their evolution in size, resources, and knowledge. Such a life cycle is influenced by the environment in which the company is inserted, as well as by the company's ability to meet market needs and generate assertive strategies.

Thus, companies must carry out the management of their scarce resources, from rational forecasts prompted by strategic systems thinking. However, those predictions are only effective when the company is 
inserted in an environment without major changes and transformations, in which it can grow from its own management. In other words, growth would come from the evolution of the industrial structure or size and outside the prospect of short-term factors.

However, with the large variations that the international economy has passed through in recent years, companies must adopt, in their daily lives, behaviors, and actions. The big challenge is when the changes and transformations occur very quickly and unstably.

Rifkin (1995) assessed that society is moving towards a model of structural unemployment, in which there will be activities related to work, but not necessarily the creation of formal posts of employment. He believed that society should return to the intangible, for example, the actions directed to the third sector. This statement leads to believe that companies should mold themselves to the macroeconomic moment, according to their structure, while continuing to take into account that there is another variable referring to human organizational talents; they need to have personal and professional growth.

The way one reacts to changes and transformations is what can make the difference between what is considered normal and what can be termed as creative, innovative, and enterprising, as highlighted by Adizes. When a group of companies can standardize forms of reaction to changes, it is possible to categorize them as generic strategies, starting from structural changes of a given economic sector. The reactions may originate from a differentiated perception of the company, from other variables, and within the global vision of their managers. In this sense, it can be affirmed that there was a rift between simple systemic thinking and the possibility of actions that enable scale, productivity, and quality gain. The great challenge is to perceive this new vision and know when to start the changes.

Prahalad and Hamel (1990) commented that it is necessary for the company to identify its core competencies and combine them with their collaborators, in order to obtain superior performance. Dosi (1998) complemented that innovation comes from discovery and experimentation, the development of new products, new production processes, and new organizational arrangements.

Drucker (2006) noted that the entrepreneur transfers economic resources from a lower productivity sector to a higher sector and one having a higher income. In fact, one of the initial propelling forces of entrepreneurship was the attempt of the companies to free those rational aspects of resource management from the intangibility of acts and so-called entrepreneurial situations and consequential results. Sometimes, the inability of the companies to generate results can lead to the abstraction of the entrepreneurship, as a strategic excuse of their managers. Human talents must realize that, sometimes, their skills and competencies are stronger than the corporate walls.

\section{Human Point of View: Need to Differentiate and Grow}

Adaptability is part of human history. The concept of resilience that comes from physics, in business administration, refers to the adaptability of the individual facing internal challenges and especially those from outside the company, referring, in this case, to action and positive reaction.

Bowen (2014) argued the need for strategic planning and scenarios, requiring adaptation depending on the degree of uncertainty of the internal and external environments of the company. People and the other features are critical for planning and implementing strategies, but cannot be directly related to the processes, but rather the results tied to the market. Considering the need for differentiation and competitive positioning, companies and people should not only deal in a reactive manner with the market, but must create constant corporate and 
personal challenges that aim at anticipation and perpetuation, or at least more frequently, entrepreneurial, creative, and innovative actions, which would lead to new business scenarios. Resilience, in fact, is usually associated with the individual's capacity to identify opportunities and solutions from adverse situations, adapting and organizing proactive actions, out of, among other practices, positive psychology as a form of corporate protection.

In the new economy, if that is how the post-crisis scenario that started in 2008 can be called, the main economic asset is not in physical resources or even in technology, but in people's minds and in how companies can identify and capitalize on the knowledge, actions, postures, and attitudes of their employees. Davenport and rusak (1999) pointed out that it is necessary to recognize knowledge as a corporate asset and understand the need to manage it and surround it with the same care dedicated to obtaining value from other more tangible assets. To undertake, the individual not only must have the motivation to do something new or different, but to do it well, so as to contribute financially and economically with him/herself, the company and society. Thus, the act of thinking in an entrepreneurial way must be accompanied by actions and procedures that comply with the company as well as the society, since rights and obligations are created, generating an interrelation between the parties. This is the difference between a mere entrepreneur and a businessperson. The latter assumes legal and lawful responsibility with his/her internal (employees) and external (with its suppliers, for example) market, generating taxes that are reverted to the society, and often promoting technological growth. In addition, this is where entrepreneurship can communicate with innovative activities.

In Brazil, due to informal labor market particularities and in the sense of making it more formalized, there is the presence of the individual entrepreneur, who is the one that works alone and obtains a business legalization permit as a small businessperson.

The solo entrepreneur can direct his/her efforts to the so-called creative economy. The Ministry of Culture in Brazil, through Decree 7743, of June 1, 2012, created a Secretary for Creative Economy (Retrieved from www.cultura.gov.br), "with the mission of conducting the formulation, implementation and monitoring of public policies for local and regional development; giving priority to the support and encouragement of professionals, and to micro and small creative Brazilian enterprises".

Brazilian initiative is based on the tendency of the innovative idea of Howkins (2001) which discusses the possibility of individuals exercising their imagination in order to generate economic value. Thus, the creative economy involves the creation, production, development, and distribution of products and services, based on knowledge, culture, and creativity as productive resources.

The UNCTAD (United Nations Conference on Trade and Development) has studied and analyzed this business mode in the world, due to its importance for social and economic development of nations, especially those developing ones.

Both the individual entrepreneurs, as well as those from the creative economy, allow for resource and income democratization, thus socially benefiting a region. They also serve as a means of technological innovations, seeing that they decentralize research and development and insert intangible motivation that is not always found in large companies.

The start-ups, so-called investor-angels, that apply resources, mainly in financial companies, have increased in Brazil in recent years, according to the National Conference of Angels of Brazil, which is a non-profit organization dedicated to entrepreneurship investment. It is the responsibility of the entrepreneur that goes after these sponsor-angels. 
In addition, business incubators are a strong reference of how good ideas can arise from market needs, being one of the most effective ways for developing new ventures. According to the Portal Brasil (2014):

In the country and in the world, statistics show that the mortality rate of companies that go through the incubation process is reduced from $70 \%$ to $20 \%$ in comparison with normal companies. The business incubator stimulates entrepreneurship in that it strengthens the companies in their early years of existence and prepares them to survive on the market. Another reason for a greater chance for the success of companies installed in an incubator is to grasp the best projects and select the most capable entrepreneurs, which then extends the possibilities for the success of these companies. (p. 7)

Incubators emerged in Brazil during the 1980s. They generally offer physical space, where companies are incubated, facilitating management, communication and a relationship between the parties. The early years, especially the first three, are essential for a new venture, because a lack of experience and knowledge of administration can bring about numerous problems, especially in regards to the lack of working capital management and marketing, among other aspects. The definition given above refers to a traditional incubator, but still according to the Brazil site, there are the following types of incubators:

- Technology-based incubators, offering research support, generating high value-added technology to products, processes and/or aggregated services. They can be linked to educational institutions, as well as to sponsorship from private companies;

- Mixed incubators, home to both technology-based ventures as well as traditional sectors. In this case, one can focus on economic sectors, for gaining synergy, such as those related to information technology;

- Social incubators, that support enterprises from social projects, which require sponsorship or even special development projects;

- Cooperative incubators, harboring associational enterprises in the training and/or consolidation process;

- Agribusiness companies, cultural companies, and design incubators, among others that attend specific business sectors that compose them.

Regardless of the type, incubators make a business more market-oriented, because they perform a natural selection, according to the apparent viability, aside from constructing indicators and management tools. This kind of initiative contributed to improving the survival rate of companies, calculated by the Organization of Economic Cooperation and Development (OECD). The modalities of incubators should contribute to new ventures that bring competitive advantage to the company, in order to compensate for differentiated investment advice.

\section{Innovations}

If there were no innovations, probably much of what people consume would not exist. Innovations can be defined as improvements in existing products and services, and occur in the business and personal daily lives. As an example, one can cite an English bank that, in the 1990s, faced legal difficulties to expand its branches in Brazil. In the search for process improvement, it made a strategic partnership with a Brazilian bank, outsourcing the checking accounts and the 8,900 employees of that English bank to the national bank. In fact, the idea of outsourcing the customers implicated in the resizing of the number of internal staff and enabled them to create isolated offices within the institution. As part of the strategy, the national bank handed over banking technology to the English bank and they in turn, offered international lines that increased the funding of the Brazilian bank for its customers. It is observed that activities need to be in connection with the business 
environment in which the company is inserted. Under the marketing point of view, the concept of diffusion of innovations can be used.

According to Semenik and Bamossy (1996),

The fundamental premise of this concept is that when an innovation is introduced into society, there will be a relatively standardized and predictable diffusion of that innovation through the society. The main elements of this diffusion process refer to the characteristics of innovation (product) and characteristics of adopters (consumers) who buy and use the product. (p. 279)

Ndubisi and Iftikhar (2012) concluded in a recent study that entrepreneurship and innovation have direct positive effects on the quality of the performance of the companies. Thus, these should not restrict their approaches only on aspects related to their internal people, but must pay attention also to the entrepreneurship and innovation into new markets in order to remain profitable and ahead of competitors.

An innovation is useless, unless it is applied on the market. Therefore, it is essential that its acceptability, introduction, and development on that same market be planned.

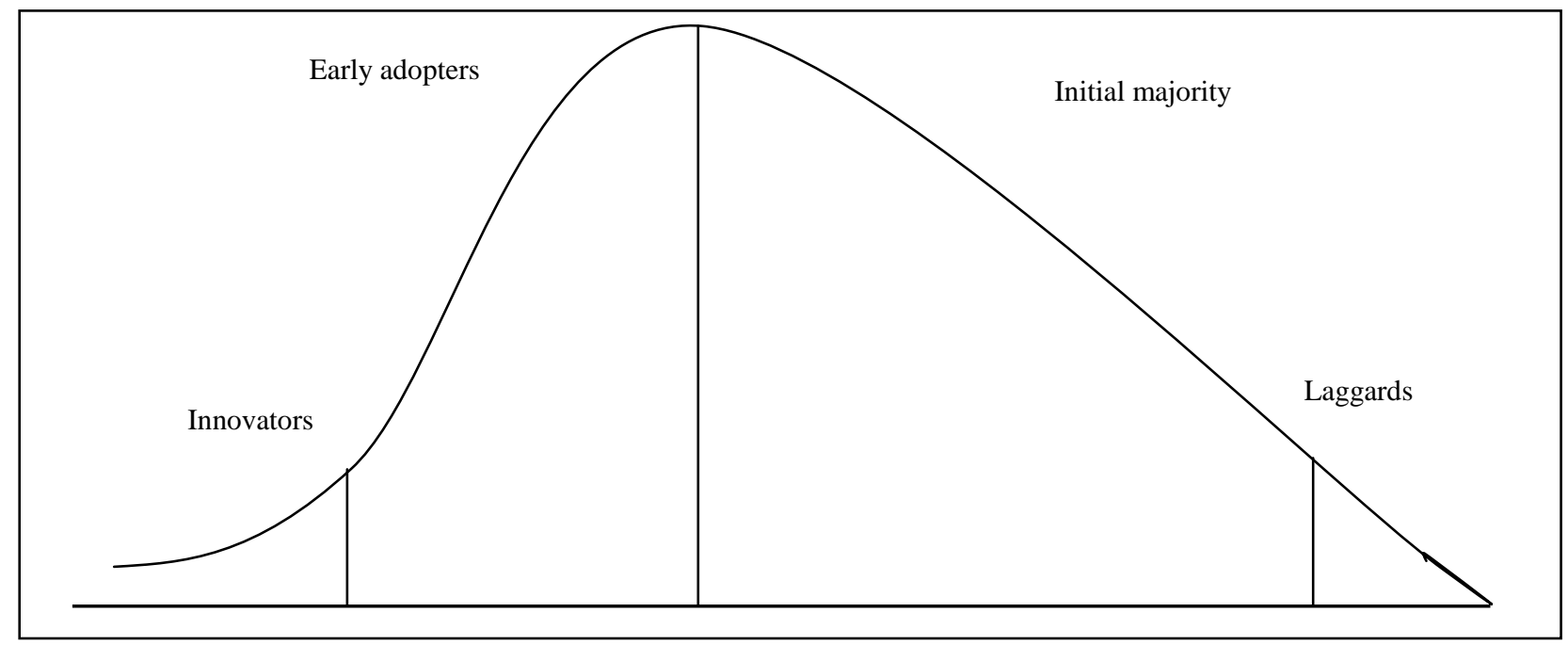

Figure 1. Dissemination of innovations: Categories of adopters. Source: Semenik and Bamossy (1996).

It is noteworthy that, although the definition of the authors has a marketing slant, the application itself in society, as a whole, refers to the reflection of other factors such as industrial structure, technological level, and education and teaching. They are closely interconnected, whether from the point of view of the company or the point of view of the market. The perception of the usefulness and the complexity of the product can accelerate or decrease the acceptance and adoption of the concept time, depending on the characteristics of macro-environmental factors of where the company is located, as well as the intensity of the company's communication, in the sense of introducing and stimulating this new concept. By direct logic, Figure 1 categorizes four types of groups of people, from a psychographic segmentation:

- Innovators: They are consumers who generally have higher purchasing power, social, education, and cultural levels. They can be classified as experimenters and serve as reference models to other future consumers;

- Early adopters: They are those using the innovators consumption as a reference point; they consume by counseling (recommendation); 
- Early Majority and late majority: They represent those who adopt the behavior from other economic and social groups, from its popularization;

- Laggards: They may be those consumers with possible rejection, skeptical or even without any interest in the proposed concept.

This classification, according to Figure 2, of consumers refers to gradual innovations, and not radical ones, which are very relevant leaps that transform society, companies, and individuals, such as the internet.

\begin{tabular}{|c|c|}
\hline Incremental & Radical \\
\hline $\begin{array}{l}\text { Extension of existing products or processes; } \\
\text { Well-defined product characteristics; } \\
\text { Competitive advantages in low cost production; } \\
\text { Frequently developed in answer to a specific } \\
\text { market need; } \\
\text { Consumer stimulated. }\end{array}$ & $\begin{array}{l}\text { New technology creates a new market; } \\
\text { Innovation researched and developed in a } \\
\text { laboratory; } \\
\text { Superior functional performance when compared } \\
\text { to "old technology"; } \\
\text { Specific market opportunity or arising from } \\
\text { secondary worries; } \\
\text { Stimulated by technological development. }\end{array}$ \\
\hline
\end{tabular}

Figure 2. Continuous innovation scale. Source: Mohr, Sengupta, Slater, and Lucht (2011).

Incremental innovations are those that represent the evolution of a pattern, and are perceived by the consumer as quality gain and usefulness of a product. They can occur in the most diverse segments. In the agricultural sector, for example, you can see a gradual evolution of planting and harvesting techniques, as well as for animal breeding and slaughter, or even on conservation and commercialization of the byproducts. Such an evolution was so clear and strong that in the 1980s the term agribusiness arose, a new perspective stemming from the dimensioning and management of agricultural and livestock activities. With the introduction of genetics and transgenic crops, agriculture suffered radical innovations, with perhaps more bruising results. In this way, innovations, whatever they are, should bring transforming results and changes to a society.

\section{Creative Aspects}

Creativity can be linked directly to marketing aspects relating to communication, advertising, and marketing. Nevertheless, the concept is much broader, considering that the focus lies on the individual and their particularities. Part of the creative process is related to the environment in which the individual is inserted and the possibilities of how the company can improve this environment by awakening and developing a creative genius in other individuals. In addition to undertaking and innovating, creativity can facilitate and optimize the changes and transformations needed, combining efforts and resources. It can happen even in traditional and conservative companies, if the organizational culture is in accordance with the goals and corporate objectives.

According to Munhoz (2005),

Creativity is a human skill that can only be recognized and evaluated from the results it produces. This is a multiple faceted process and target of numerous definitions, due to the complexity of the concept that encompasses some of the dimensions: relative to the procedure, the characteristics of a creative person, the product that is created and the facilitating environment, or not, of the creation process. (p. 214) 
The dimension of creativity thus involves the individual, with his/her characteristics and peculiarities, fruit of his/her existence, experience and view of the world, in the environmental context in which it is inserted. It involves the business scope, which may offer the individual exogenous variables, motivating and leading $\mathrm{him} /$ her to a certain type of behavior that might then lead to building competence, creativity, and subsequently the needed results. There indeed lies a problem. Unlike the advertising and publicity area, where it is possible to measure the cost of the investment in creativity, other sectors may not have this possibility for measurement, aside from the financial results of the business. Hence, the creative process sometimes is confused in the daily business with the innovative process. Observe some examples that allow a better understanding of this differentiation: One cannot apply the creative process in the development of a new drug, but there can be innovative technology in research, development, and production. From the point of view of gastronomy, it is possible to use the food from the plate creatively, but under the prism of nutrition, it becomes dangerous, and may cause a health risk to the individual.

Capodagli and Jackson (2000) commented that,

There are two basic schools of thought on creativity in business. The first insists that researchers and other innovators be given the loosest possible network, to allow new projects and ideas to develop by own impelling force and with maximum independent decision-making. The second school requires that the reins be kept steady and that generating ideas is part of the corporate process and like other parts, it is carefully controlled. (p. 122)

The authors' statement leads to another reflection. The company manages to, in its strategic plan, invest in innovative human capital in their budget and, subsequently, in the management and control of the results, but not in the creative aspect, that stems from the subjectivities, without allowing for the prediction of results.

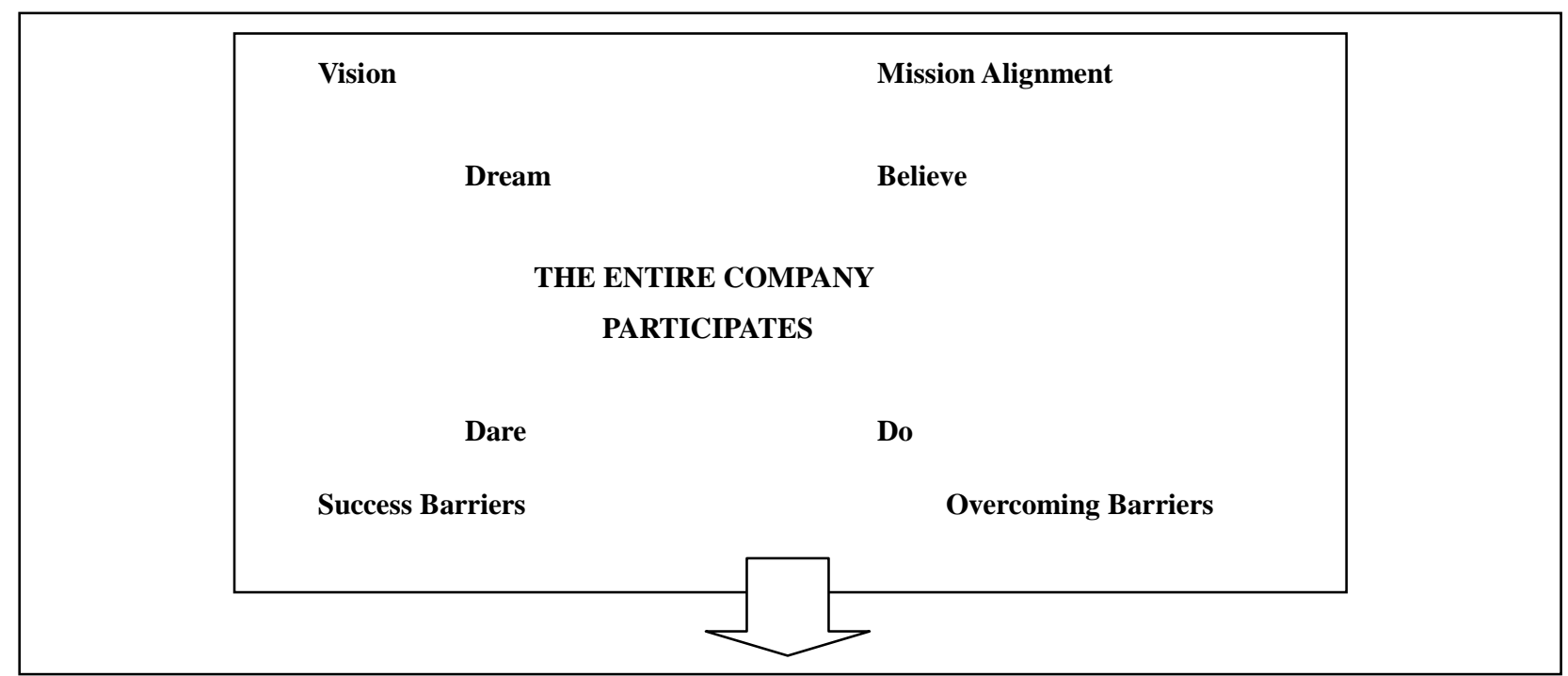

Figure 3. Process dream, believe, dare, do. Source: Capodagli and Jackson (2000).

Thinking in this way, both entrepreneurship and creativity should be encouraged by the company in order to awaken the abilities and skills of their particular workforce. As in Figure 3, the company must give a freedom to manage its workforce so that they contribute positively to the process and its results. For the innovative process, you can insert the procedures and actions in a more objective plan. In relation to creativity and innovation, practices should be carried out from concrete results. 


\section{Necessary Human Skills}

It is possible to affirm that individuals have characteristics, qualities, skills, and competencies, without the necessity of going deeper into psychology:

- Features refer to the physical aspects of a person. Individuals may be tall, short, thin, or over weight, among other physical aspects that do not (or at least should not) interfere in the actions of a person;

- Qualities are virtues that exist and are recognized by other people. Therefore, a certain individual can have good communication skills, which can bring about an important differentiation for that person within a social group;

- Skills refer to the process of how to do something. Thus, an individual can speak a language well, perform tasks, and behave according to standards and procedures;

- Competencies are related to results. Therefore, people can use the language as instrumental in persuasive negotiation, as well as leading a group of competent individuals to obtain more synergistic results.

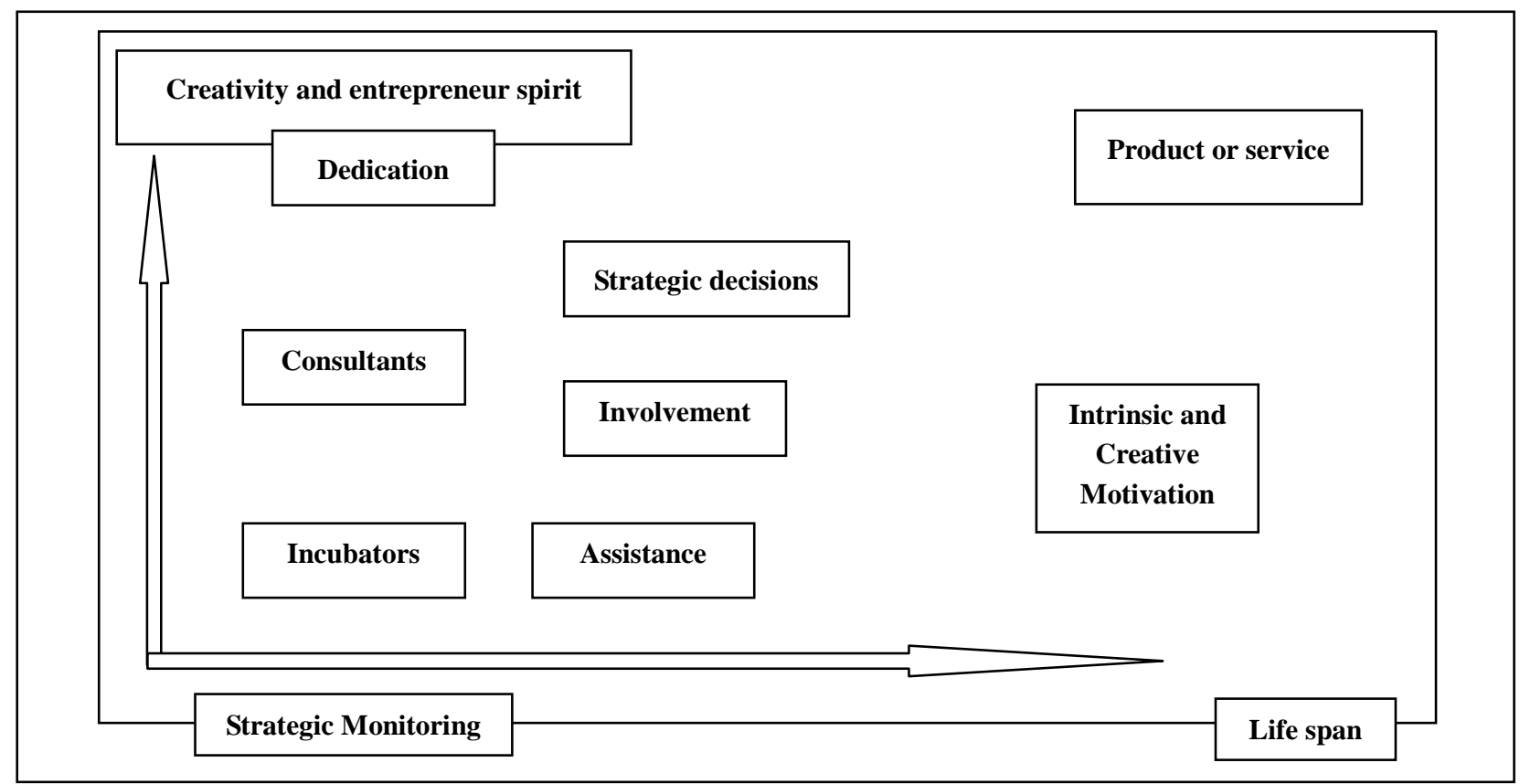

Figure 4. Analysis of entrepreneurship and creativity.

The level of involvement and commitment of an individual can be related to several factors, such as his/her professional life cycle, the life cycle of the company, as well as the aspects related to self-assertion and a need for overcoming challenges. Depending on the actual situation, an individual may be more prone to entrepreneurial and creative activities and the consequential level of results. Depending on the degree of maturity, an individual may look for more challenges and consequences.

Analyzing Figure 1 and 4, in conjunction with the theory of life cycle proposed by Geus (1999), one must diagnose the moment of the company as well as their employees, contextualized with the environmental in which the company is inserted. Depending on the diagnostics results, one can take certain actions and strategies to maintain the consistency of the company's resources - in this case, represented mainly by human capital, to maintain the sustainability of the business. 


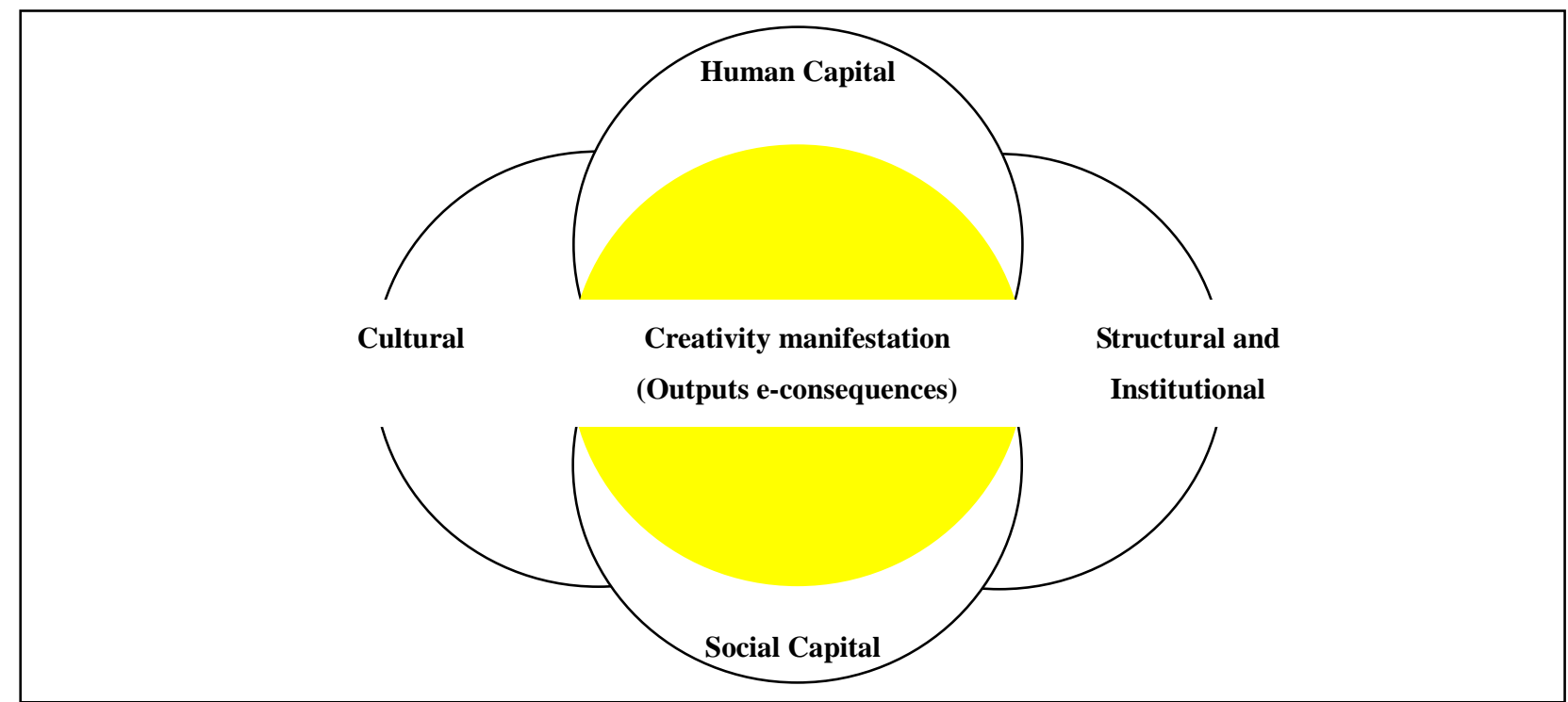

Figure 5. Consequences of creativity. Source: Retrieved from http://unctadxiii. org/en/SessionDocument /ditctab20103_en.pdf.

In fact, the environments conducive to changes can be highly fertile for challenges, but the challenges can be endogenous, being part of the characteristics of the individual. These endogenous challenges can contribute to the manifestation of creativity and generate increased general capital, represented by Figure 5 .

For skills development, it is possible to identify what skills are required and how to promote actions aiming at developing them. According to the Foundation for Leadership and Learning, the skills can be categorized as general and specific competences, according to Table 1.

Table 1

General and Specific Skills

\begin{tabular}{|l|l|}
\hline General Competences & Specific Competences \\
\hline Personal and Educational & $\begin{array}{l}\text { (1) Accept moral postures, ethics and those of social responsibility. } \\
\text { (2) Utilize teaching and learning theories and strategies. }\end{array}$ \\
\hline Interpersonal & $\begin{array}{l}\text { (1) Valorize people's development. } \\
\text { (2) Develop interpersonal communication and relationships. }\end{array}$ \\
\hline Organizational & $\begin{array}{l}\text { (1) Implant changes, create and innovate. } \\
\text { (2) Promote organizational development. }\end{array}$ \\
\hline Cognitive & $\begin{array}{l}\text { (1) Know the fundamentals and theories for leadership. } \\
\text { (2) Research and analyse data. } \\
\text { (3) Manage formation and generate knowledge. }\end{array}$ \\
\hline Professional & $\begin{array}{l}\text { (1) Solve problems and make decisions. } \\
\text { (2) Undetake and administrate. } \\
\text { (3) Plan and implant projects. }\end{array}$ \\
\hline
\end{tabular}

Source: Retrieved from www.tfll.org.

In the same way as the Foundation for Leadership and Learning relates directly to leadership skills, several authors converge on similar categorizations. Therefore, for a better understanding of that which is in discussion, this paper adopted here the referred categorization as a reference for the contextualization of enterprising, creating, and innovating.

It notices that the categories of the competencies cited act in a unique and complementary manner, so that each individual can choose between groups of general or specific skills. A financial administrator might, for 
example, be able to carry out his functions well, and have a cognitive, interpersonal, organizational, and professional skills group to enable him to achieve the expected results. A doctor may have, on their list of competencies: interpersonal, cognitive, personal, and professional. In this way, it is up to each individual to identify which skills they need to achieve their personal and professional goals.

\section{Entrepreneurship, Creativity, and Open Innovation}

Both competences and skills can be developed from stimuli and external influences, such as the environment in which one lives, the company, and the teaching environment.

It can be affirmed that human skills can also be those related to entrepreneurship, creativity, and innovation, as long as they bring contributions to someone. However, the management of the processes is of fundamental importance for results to be achieved.

One of the ways of getting results that are more consistent is to manage the company in order to diversify the structure of these talents by hiring individuals with different skills from those that the company usually has on its workforce. Another point is the conciliation of the personal life cycle with the corporate goals and objectives-a stage where the manager should have the ability to administer him/herself and delegate this decentralization of power to his/her peers and subordinates. However, one of the biggest challenges for the incorporation and acquisition of these skills is working with processes of changes and gradual transformations. In addition, one of the most difficult is habit changes, be they corporate or personal. Habits often reflect the personality and way of being of the individual and are hard to disengage oneself from them. Under the corporate point of view, the cost of the changes can be evaluated through management criteria and indicators.

In short, there will be no entrepreneurial capacity, if there is no proper competence. Innovation will not be possible, if there is no enabling, planned, and organized environment for its development. There will be no room for creativity, if there is no will on the part of the individual. Finally, if there is no will to grow and develop, no creative or innovative entrepreneurial activity will be able to emerge, in a contributive manner for society as a whole. There will be only good answers to the questions and everyday longings from the differentiated manner in which people question the view of the world.

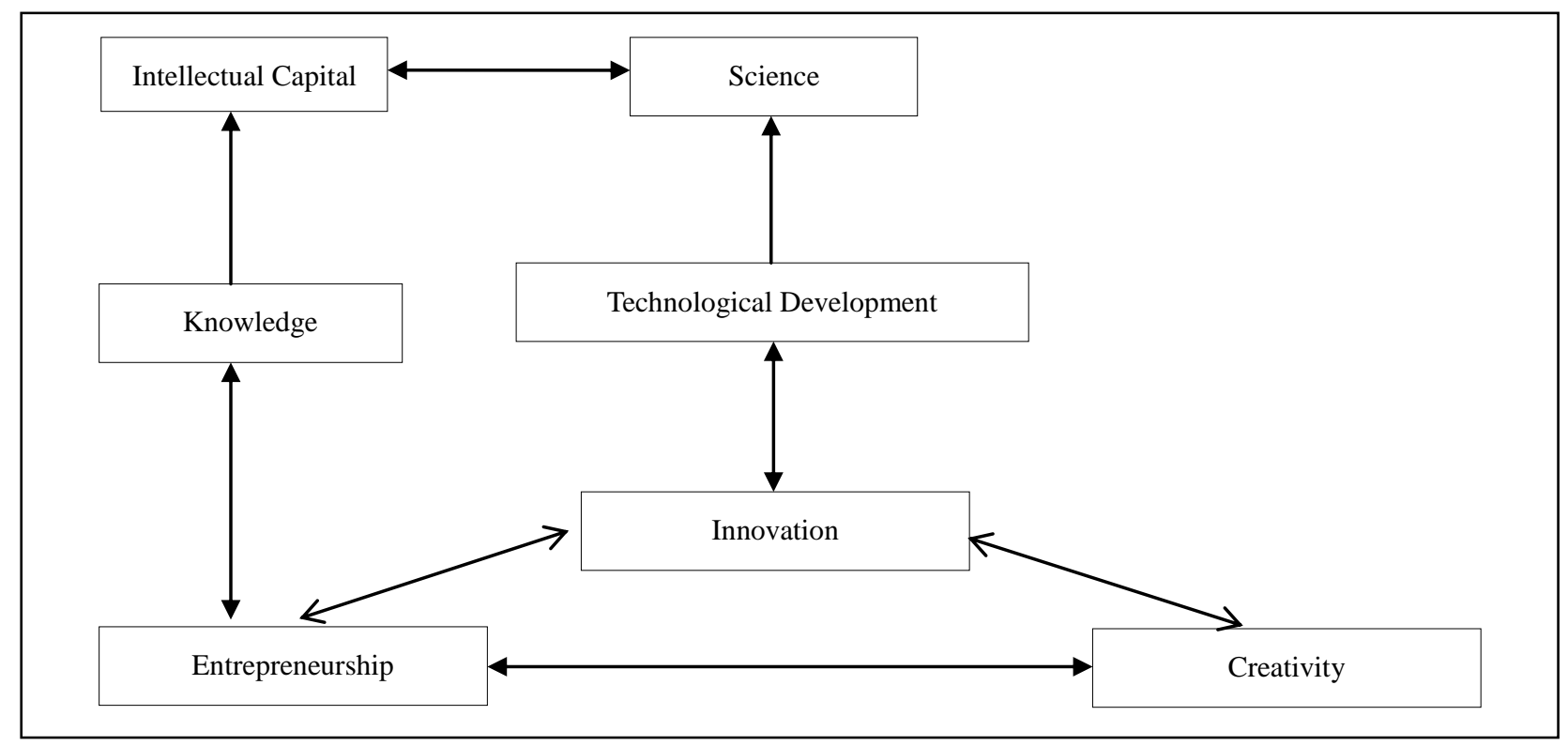

Figure 6. Administration: science or art? 
The science of administration, as highlighted at the beginning of this article, covers different areas such as logistics, finance, production, personnel management, and marketing. The company, with the participation of its employees, can find its continuity and longevity by means of process management and indicators, which make it possible to organize and plan the use of resources and organizational actions.

In conducting the company's path, it is necessary to use the competences mentioned, in order to make the administration more than a set of rational processes, which they must manage, but rather a business modeling in a more skilled and intimate manner, transforming science into a model of art, as observed in Figure 6.

\section{Case Studies}

According to a survey conducted by Amatucci (2000), there are a number of skills and attitudes (ethics, personal, social, interpersonal sensitivity, a view of the future, and underlying learning) as well as knowledge representing professional profile of the Brazilian administrator. To demonstrate that administration is not only an exact science, but that it comes from several other applications and knowledge based on reasoning, analysis and qualitative interpretations, human purposes, a series of examples showing such practices as states of art. Contextualizing with the referred study as described in the methodology, case studies that allowed for the qualitative analysis of the sample involving issues related to entrepreneurship, creativity, and innovation were applied.

Case 1. In a department with 50 employees, only one of them exercised his/her activities in a normal way, with no differential, faithfully fulfilling all activities in a six-hour shift, established by the company. At the end of the year, the company offered a bonus amounting to a salary, to be divided among the 10 best evaluated. When they changed the manager, the professional who took responsibility negotiated an increase of financial resources with the Board and remade the bonus distribution policy, making it understood that, each one of the employees had responsibility over the outcome of the department. Then, at the end of the year, they all received the award, including the employee mentioned above, who came in last place, but for the first time received a symbolic gratification of $10 \%$ of his salary. After this award, this employee changed his behavior, participating more actively in the work, including suggesting changes in his activity, becoming one of the most prominent in the department.

Case 2. A certain English multinational established in Brazil, had a program for selecting trainees open to employees as well as the public. They offered it once a year, with the goal of identifying 16 young graduates, for two years of training to take over the sub management units of the company. The screening program involved nine stages and those approved should accompany executives with vast experience in their daily work, in branches all over the whole country.

A particular employee, quite motivated, enrolled in the selection program for three consecutive years, and was able to reach the third step of the process. He tried for the fourth time, but failed to mention on the chart that he was a company employee. The next time he was able to go to the eighth selection phase, but failed in the last (ninth), which was carried out internally-remembering that different companies had carried out the previous steps externally. From then on, he realized that the selection program was biased towards its employees and they offered it as a way of motivating the team, but at no time was it the company's goal to select employees as trainees. After this situation, he became demotivated and started looking for other opportunities on the market. After 10 years of selecting trainees in this way, they discontinued the program, because they noticed that most of those who were accepted, after training, were co-opted by the competition with better jobs and salaries. 
Case 3. In 2011, the Japanese came under the aegis of a catastrophe, as a result, possibly from cooling failures in nuclear power reactors based on Fucushima. A similar event, such as that in Chernobyl in 1986, could have happened, generating a worse scenario than that faced by the country in World War II. However, the different external features and technologies offered by the United States of America and European countries led to a reduction of aggravating possibilities which could have occurred in the short term. Japanese economy has a considerable GDP and GNP, with a part of their companies based outside Japanese territory. For the first time, they considered the possibility of the non-existence of a national territory because of the leak, which could have made it uninhabitable. However, as human and financial resources assets were outside this territory, it was up to the government to find a new form of management to govern the population. Thankfully this fact did not occur. Nevertheless, worthy of distinction was the subservience of the population before the country's government, which considered that there should be a need for maintenance planning and subsequent economic and social growth. The predictions are that the Japanese economy will start to grow and achieve a level better than before the crisis. An important aspect, the cultural, calls the attention of Western outlook. This paper refers to the episode of the mobile hot tub, offered by the soldiers of Japan's Defense Force to the population of the worst affected areas (Ofunato and Rikuzentakata), aiming at easing the people's suffering while facing those difficulties, as well as, improving their self-esteem and motivation. It should be noted that economic and cultural diversity is important factors in the chain reaction of actions, because behaviors are molded from the environment.

Case 4. The candy market in Brazil, in the 1960s, was dominated in the candies segment by two brands: Juquinha and Soft candies. With low competition and a stable and expanding consumer market, one would hardly consider repositioning the product and searching for an external market. Juquinha candies, however, is one of the good examples of that a visionary company can grow and expand their sales, by means of sales repositioning. When it was founded in, it produced cold drink powder and in the following decade, it began producing candies with a difference: fruit flavors. In the 1980s, as the leader in the domestic market, it began to export to the United Arab Emirates and the United States of America, where the candies are regarded as premium products. In this way, two-thirds of its current production is committed in sales to about 50 countries and the remainder on the domestic market, where competition is fierce and the population does not consider a candy with differential as a competitive advantage. In other words, from the market viewpoint, the company sought, in an enterprising manner, the international market via direct export, as the primary entrance and operational strategy in international markets, ensuring their survival and future sustainability. Without this, the company probably would have great difficulty in fighting for the domestic market at present. In this way, one understands the importance of entrepreneurship, creativity and innovation on the international scene, where successful practices depend essentially on how the company and people interpret, analyze, and put into practice the international marketing actions.

Even more, according to Amatucci (2000), the main competence generators of a professional profile are: demands related to the techniques of the profession of administrator; the globalized society; demands of the current stage of Brazilian labor; regional labor market demands in São Paulo and inductors of the personality of the school. In general, the implementation of the case studies made it possible to have better knowledge of the boundaries of the sample, with an average score of nine points, by deducting directly that the didactics used were able to meet their goals. On the other hand, in consultation with company managers where students develop their professional activities, with regard to aspects of professional use, a similar average was obtained, which proved the direct relationship among the activities carried out in relation to market expectations. Although part of the 
responsibility of education and professionalization is derived from government policies, Lin, Shen, Sun, and Yu (2008) highlighted the importance of higher education in order to improve the performance of the enterprises and their technological base, greatly contributing to the development of a nation.

\section{Conclusions}

The importance of the science of administration may be perceived through its contribution to the companies. The responsibility of part of the learning of this science and the application of simulations is the responsibility of the IHE. Companies develop an important social and economic role as catalysts for private and public resources stemming from the knowledge of their internal collaborators. Through labor and taxes, companies contribute significantly and their longevity ensures the sustainability of the entire social system. There is no social without economic and financial contribution, but there may be economic without the social. Thinking in this way, companies need to contribute part of their resources to the society, through its perpetuation, inserting the systematic entrepreneur, innovative and creative way of thinking. With such ideologies, the company can democratize job opportunities and financial resources, creating and stimulating different challenges entrepreneurs.

The process of undertaking, creating, and innovating can occur from need and/or opportunity. If individuals can enter into their daily lives, they will have more success than those who only practice actions from external stimuli. There is no purpose in having goodwill and creative ideas if there is no space or even a competent business model that can absorb them successfully. Such a process should be embedded within a systemic vision, but not airtight, in the sense of acting synergistically with the company's strategic planning and market fluctuations.

According to various studies, such as Peng, Zhang, Fu, and Tan (2014), innovation is one of the critical factors for the success of contemporary companies, where it is necessary to know their driving forces, especially those related to the internal public, their training and knowledge, as well as their sharing such content with the organization. As for political implications, this article sought to contribute significantly in the contextualized analysis of value systems involving the IHE and mainly businesses and the market, permeating all levels with the tools related to entrepreneurship, creativity, and innovation. At times, this paper has a fragmented and reductionist vision of the different components of a society and the reflection on the importance and interconnectedness between them can encourage practices aimed at the sustainability of the process, a synergy that favors the construction of a new professional within companies. For future study, this paper intends to repeat and comparatively analyze the results, including or deleting variables, in order to establish a standard that makes results, which are more concrete, a possibility.

\section{References}

Adizes, I. (1999). Gerenciando os ciclos de vida das organizações. São Paulo: Pearson.

Amatucci, M. (2000). Perfil do administrador brasileiro para o século XXI: Um enfoque metodológico (Tese de doutorado, Faculdade de Economia e Administração, Universidade de São Paulo, São Paulo, SP, Brasil).

Bowen, G. (2014). Estrategy formulation in uncertain environments. Baku: GBTA.

Capodagli, B., \& Jackson, L. (2000). O estilo Disney. Aplicando os segredos gerenciais da Disney em sua empresa. São Paulo: Makron.

Chandler, A. D. (2001). Strategy and structure: Chapters in the history of the industrial enterprise. Cambridge: MIT Press.

Davenport, T., \& Prusak, L. (1999). Conhecimento empresarial. Rio de Janeiro: Campus.

Dosi, G. (1998). Technological paradigms and technological trajectories: A suggested interpretation of the determinants and directions of technological change. Research Policy, 11(3), 147-162. 
Drucker, P. F. (2006). Managing in turbulent times. New York: Harper Collins Publishers.

Foundation for Leadership and Learning. (2005). Home. Retrieved from www.tfll.org

Gergen, M. M., \& Gergen, K. J. (2006). Investigação qualitativas: tensões e transformações. In N. K. Denzin, \& Y. S. Lincoln (Eds.), O planejamento da pesquisa qualitativa: Teorias e abordagens (pp. 367-388). Porto Alegre: Bookman e Artmed.

Geus, A. de. (2002). The living company: Habits for survival in a turbulent business environment. Boston: Harvard Business Review School Press.

Howkins, J. (2001). The creative economy. New York: Allen Lane.

Kotler, P., \& Armstrong, G. (1999). Princípios de marketing. São Paulo: Prentice-Hall.

Lakatos, E., \& Marconi, M. (2003). Fundamentos da metodologia científica. São Paulo: Atlas.

Lin, G. T. T., Shen, Y. C., Sun, C C., \& Yu, H. C. (2008). Assessing national innovation policy: A comparative study (Global Business and Technology Association, Managing in an Interconnected World: Pioneering Business and Technology Excellence Madrid: GBTA).

Markatou, M., \& Stournaras, Y. (2013). Innovation for entrepreneurship: Is new technology a driving mechanism for the creation of a Firm? Journal of Global Business and Technology, 9(2),1-1.

Mohr, J., Sengupta, S., Slater, S., \& Lucht, R. (2011). Marketing para mercados de alta tecnologia e de inovações. São Paulo: Pearson.

Munhoz, M. (2005). Liderar com criatividade, uma competência humana. São Paulo: Saraiva.

Ndubisi, O., \& Iftikhar, K. (2012). Relationship between entrepreneurship, innovation and performance: comparing small and medium-size enterprises. Journal of Research in Marketing and Entrepreneurship, 14(2).

Peng, J., Zhang, G., Fu, Z., \& Tan, Y. (2014). An empirical investigation on organizational innovation and individual creativity. Information Systems \& E-Business Management, 12(3), 465-489.

Portal Brasil. (2014). Micro e pequeno empreendedores ampliam possibilidades de negócios com a Copa 2014. Retrieved from http://www.brasil.gov.br/economia-e-emprego/2013/04/micro-e-pequenos-empreendedores-ampliam-oportunidades-de-nego cio-com-a-copa-de-2014

Prahalad, C. K., \& Hamel, G. (1990). The core competence of the corporation. Harvard Business Review, 68, 79-90.

Rifkin, J. (1995). The end of work: The decline of the global labor force and the dawn of the post-market era. New York: The Putnam Berkley Group, Inc..

Schumpeter, J. A. (1949). Essays on entrepreneurs, innovations, and business. London: Transaction Publishers.

Secretaria da Economia Criativa. (2012). Ministério da Cultura. Brasil. Retrieved from www.cultura.gov.br

Semenik, R. J., \& Bamossy, G. J. (1996). Princípios de marketing. Uma perspectiva global. São Paulo: Makron.

United Nations Conference on Trade and Development. (2010). Creative economy. Report 2010. Retrieved from http://unctadxiii.org/en/SessionDocument/ditctab20103_en.pdf 